\title{
Justifying Logic of Plato for Stranger's Method in Politicus
}

\author{
By Mostafa Younesie
}

\begin{abstract}
One of the salient dominant features of Politicus is the necessity and application of the method on the part of the dialogue leader in order to reach a definition of the intended term. With regard to this point here the proposed logic of the stranger through the pen of the dialogue - writer will be explored and introduced.

We begin with what can be Plato's conception of method in its both classical platonic versions. It will be shown that we can speak of logic and its application in this dialogue. Here the intended logic is composed of these five parts: Whole - Division - Differentiation - Combination - Analogy. Accordingly, the subject-matter of Politicus is considered a whole that as any other composition is dividable into its related parts. Some parts can be differentiated and others can be combined with each other in meaningful and acceptable ways. Then in this relation we can refer to suitable analogies in order to enhance and vindicate the proposed differentiations and combinations.
\end{abstract}

When reading the late dialectical dialogue of Politicus as a member of a set, we experience the application of a more or less sustained "method" in order to deal (the detailed meaning of it will become clear in the following) with "Politicus/statesman." It may be inferred that the aim of the writer is to define the whoness of "statesman/ $\tau \iota$ то $\varepsilon \sigma \tau \iota$ and at the same times the whatness of his pertinent knowledge in the form of statesmanship/ $\tau \iota$ זo $\tau$ $\varepsilon \sigma \tau$." And the applied method wants to attain a specific goal and does not want to do many things with one hand. But let us see whether the Stranger/Guest really seeks to define the statesman and if yes, what can it mean for him in this particular dialogue and what is its background justifying logic. In other words, Plato's exploration of the logic of the applied method for defining Politicus is the aim of this paper.

Although according to Kneale and Kneale ${ }^{1}$ logic in the favored meaning of the modern period is introduced by Alexandrian Aphrodisias in the third century A.D. still before that time we can observe the existence and application of the logic in the classical Greek more or less in the form of the valid inferences containing both argument and principles of validity.

Nevertheless, we should not expect that every kind of speech or text have or give us proof of such a narrative or story. Therefore it is necessary that we

\footnotetext{
*Assistant Professor, Tarbiat Modares University, Iran.

1. William Kneale and Martha Kneale, The Development of Logic (Oxford University Press, 1985), 7, 10.
} 
have a classification of the extant texts and accordingly demand proof of them. In this relation in classical Greek we can expect that legal and judicial/political writings contain proofs more than the other kinds of texts. In other words, one of the basic areas in which classical Greek is relatively suitable to search for proofs or more precisely historically validity principles and valid arguments is judicial/political texts that mostly belong to before Plato.

In regard to Plato it may be said that in proportion to the subject matter and the case under consideration in his own ways he deals with the principles and foundations of valid arguments: from where to begin arguments; what are the criteria of being false and true; realization of valid argument; definitions and the like² (but as we go it becomes clear that it is not the entire story).

In order to have a primary outline of the totality of Politicus we read that Stranger/Guest wants to define the statesman correctly through a specific method that has a beginning and after a valid referential process that reaches to the end. In this context this guiding interlocutor does not limit himself to the pertinent word but seeks for the common characteristics in the individual and particular entities and in order to achieve this goal he chooses a specific method, since it seems that for him that a rule valid method leads to valid definition and invalid one to the opposite. Thus here the logic or syntax of the Stranger/Guest definition of the statesman will be explored with regard to the classical attic Greek as an issue which has not been too commonly explored.

\section{Outlining the Method: The First Initial Part}

The repeated and emphatic theme of this dialogue through the Eleatic character is the necessity of following a scientific method in their demonstrations (258d; 265a; 266d; 268d; 285d; 286d). Besides, he goes beyond merely mentioning and describing and in a word applies his meaning of method. His favored way for a collective search is gradual and phased which is based on division and collection that we can summarize it under the title of "dialectics."

Therefore doing a dialogue about statesman needs preparation, exercise and skill in understanding an application of the scientific method that here means "dialectic." And in this relation we can consider the definition of politicus as a case study (285D) in discussing and applying the pertinent method. Interestingly, what is usually called the ancient logic can be put under dialectic $^{3}$ and the latter is a shorthand method and as an editorial clue we may read it as a "logical approach to kingship."

With regard to this emphasis we outline the gradual/phased method of the Stranger/Guest from the beginning down to the end in this order: Whole -

2. Ibid., 17.

3. Ibid., 7. 
Division - Differentiation - Combination - Analogy. Initially, in regard to the whole we may say that he begins from a whole that has some parts and is not simple and it gives him capability and maneuver in order to then divide it. Division is the second step and as we mentioned dialectic begins with the dichotomy of the universal into two rational and natural kinds or set that the researcher holds one of these kinds and put the other one in parenthesis (258c). In other words, division is searches the different qualities and properties of a thing and in a gradual process the related researcher takes the appropriate quality and epoche the other one and after some stages reach to the favored item. Therefore by division of a universal into particulars and extensions and thereby differentiate them from each-other the division descends from one up to many down.

Up to now it became clear that collective research begins with the consensus of the interlocutors about the starting category which is "episteme" in order to cognitively define the statesman as an individual. Then with regard to the existent, concrete and external extensions this agreed category in a gradual process will be dichotomized. It means that the Stranger/Guest with specific standards in his mind $(283 c-285 c)$ will divide "episteme" into A and Other-Than- A which holds A and brackets Other-Than-A and then divides A into $\mathrm{B}$ and Other-Than-B and continues this process down according to his intended standard until it reaches and stops at the appropriate item.

But this is the midway and through composition he wants to go from down, up. Here in politicus a composition means bringing together a combination of entities which have distinct identities and accordingly it is comparable with the logical individual and not the analysis. ${ }^{4}$

\section{Logic of the Method}

Now it is time to speculate about the justifying logic of this part of the Eleatic method by Plato. In a simple way, it seems that they want to begin their shared research with a "rational supposition" which is pertinent with the whoness and whatness of the statesman. It may mean that for the classical Greek matrix mind, dealing with politicus needs a "rational" (in comparison with "empirical") beginning and then according to the "duality" as the building block of mind division of this supposition into two parts (not less or more). If so, what factors are effective in proposing "episteme" as the rational supposition? Is there any hint in the dialogue about his beginning? In relation with the latter question we can say that according to the wordings of (258b) it is clear that this supposition is something accepted by the interlocutors at the beginning of Politicus. This

4. Wincenty Lutoslawski, The Origin and Growth of Plato's Logic (Longmans, 1897), 444 . 
acceptance may be rooted from factors such as implicit unsaid consensus, the genuine belief of Young Socrates in the relation of politicus with episteme, merely as a primary step for continuation of the dialogue, as an alternative to the dealing with sophist on the basis of "techne," and the like. As a result it can be guessed that this rational supposition is only an agreed supposition by the pertinent interlocutors but at the same time has interplays with the methodological intentions of the dialogue writer too - this aspect shows itself gradually throughout the text and when we read the whole dialogue it becomes available.

At the next step it seems that according to the classical Greek pattern of thinking, the mind divides this "rational whole" into two sub-wholes (258 b) in order to do a particular dealing with the statesman. It should be said that there are two interrelated moments in the Greek word $\delta \iota \alpha \lambda \eta \pi \tau \varepsilon o v(258 \mathrm{~b}$ ) or between "distinguishing" and "division" and at the same time this division returns basically on a "dichotomy" that can be called X/Other-Than-X - I have such a reception of Gill's emphasis on the dichotomous quality of division, in 2010, many places but specially 188, 194, 197. Therefore we should "distinguish" the related moments in the "rational whole" and accordingly "divide" them into two or more parts (in relation of both many logical faults are possible) for methodological and analytical ease, habit or by the cast of mind that Plato puts them under two parts such as X and Other-Than-X (with a wide range) that can take the one or the other for our research and if there are other forms in the text or the guiding interlocutor begins with the righthand division or the left-hand division they are not exceptions or aberrations of the mentioned schema but all are within it. ${ }^{5}$ And these divisions will be continued up to the point and limit at which further divisions are not possible or meaningful but on the contrary are absurd and inconsequential.

At the same time we can consider these the pertinent "rules of justifying logic" up to here - how to do a correct research. The suitable division is the one in which as far as possible the whole is divided into two parts in order to follow and observe an ordered and uniform (not anarchic and multiple) arrangement. And this dichotomy should be based on some prior knowledge and naturalness in order to prevent non-methodic arbitrariness and ignorance on one hand and forgery and artificiality on the other. Besides, as a rule we should distinguish between the prior and posterior or the big and small categories and in other words observe their priority and inferiority. In logical words, it means that we should first bring the genus and then its pertinent kinds and not the opposite (263a, 262b).

But yet our rules are too large and many things can be inserted into them. Logically, it means that all these are in relation to genus and kinds but it is not enough and complete therefore we should make and provide some way for

5. See for example, Kenneth M. Sayre, Metaphysics and method in Plato's Statesman (Cambridge University Press, 2006), 109, 126. 
making the domain narrower and in logic this will be realized by the distinction and differentiation of statesman from homogenous, opposite/ pseudo, forgery, rival/claimant, supportive titles and categories and each according to their own specific rationale.

\section{Outlining of the Method: The Second Last Part}

Up to here the Stranger/Guest has spoken about the statesman himself and at the same time its differentiation from the comparable categories. The justifying logic of this effort is the definition of any category in itself that denotes to its "conclusiveness" and at the same time, its distinctions from the other homologous things as its "exclusivity."

Notwithstanding, it seems that for the Eleatic the followed method is incomplete for the statesman as a logical individual is not examined yet and it should be said that in order to do this he complements his methodic discussion by introducing analogy/comparison (277c) as a customary way in ancient Greek for demonstration alongside induction and deduction. Even though we read in other dialogues of Plato his recommendation for using analogy, it is here that for the first time he presents a rather detailed theoretical and practical discussion about it in order to complete his dialectic.

Here it seems that the example is interchangeable with analogy and means judging about a particular thing through a judgment which is made in relation to another similar pertinent particular. Therefore in analogy we make a judgment about a particular unknown because there is a judgment about a particular known that in conclusive meaning has similarity with our intended case. Accordingly in the ideal example or analogy, there are four limits: the knowable or given particular; the unknowable or new particular; the reason or commonality; and the judgment. ${ }^{6}$ And it is in this atmosphere that the Stranger/Guest claims that through familiar examples and at the same time bridging and comparing them with difficult ones we can understand and explain the latter ones too $(277 \mathrm{~d})$. In this relation he begins his example from the letters (278b) and then goes towards examples such as physician; captain; musician; and gymnasium- trainer with focus on the weaver in order that through these familiar known analogies some understanding of the unknowable title of the statesman is made. And it is noteworthy that in each familiar example gradually he mentions and selects the relevant similarity and attributes and extends it to the unknowable title. With regard to the focal position of weaving and weaver, the Eleatic begins from this familiar and

6. M. Khansari, A Dictionary of Logical Terms, (Foundation of Iranian Culture, 1980), 78. 
known example and with regard to his inferences from it then extends them to the unknown case that is statesmanship/statesman.

\section{Logic of the Method}

As we mentioned, analogy or example is one of the usual methods in the classical Greek logic and in Plato's logic too. It is connected with the first part on method that is dialectic and it is in interconnection and intertwined with it so the method of dealing with politicus becomes complete and perfect/ $\alpha \pi \varepsilon Q \gamma \alpha \sigma \omega \nu \tau \alpha$ L (257b). Quoting Lane:7 "to ensure that the crucial role of paradeigma is not missed, the stranger embarks on a lengthy analysis of what it is, how it works, and why it matters" (277d - 279a). Among these pages it seems that $278 \mathrm{~b}$ in a nutshell can give us a general picture of Plato's conception of example or analogy in its Platonic meaning: "... $\pi \alpha \varrho \alpha \tau \iota \varepsilon \varepsilon \mu \varepsilon v \alpha$ $\delta \varepsilon \iota \chi \theta \eta, \delta \varepsilon\llcorner\chi \theta \varepsilon \nu \tau \alpha \delta \varepsilon, \pi \alpha \varrho \alpha \delta \varepsilon \uparrow \gamma \mu \alpha \tau \alpha$.../placed- across shown; signifying something; they become analogous". In every example, usually we want to know and become acquainted with the less known subject through the more known and familiar one therefore we put them in parallel relation with each other. This ordering is something beyond mere showing and symbolizes and hints at something that working on this symbolic core can cause and make the proposed example as par example. Accordingly, in every example and analogy there are three interlinked moments: the analogical entities; the symbolic notion; and similarity/difference with the aim of transiting of the interlocutor from true belief to knowledge. ${ }^{8}$

\section{Conclusion}

After outlining Plato's method in two complementary parts we have dealt with the logic or syntactics (these two are not completely separated yet) of his method in the forms of Whole/division/differentiation/collection /example. It is our supposition that "Sophia" is the general background against which both interconnected "Sophist" and "Politicus" dialogues in their own specific rationales are written. Accordingly, Sophia is the common context or background that with attention to it we can understand whoness and whatness of sophist and politicus. Therefore the rationale of the guiding interlocutor for beginning the dialogue by his specific form of question about episteme (epistemic approach) is rooted in a

7. Melisa S. Lane, Method and Politics in Plato's Statesman (Cambridge Classical Studies, 1998), 61.

8. Ibid., 66. 
kind of consensus about sophist and politicus as two different representations of a common Hellenic cultural background (I have inferred it from Peters). ${ }^{9}$

With regard to this agreement the basic question of the dialogue takes shape that in itself has many subtleties which should be examined as a dimension of

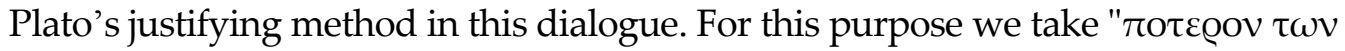

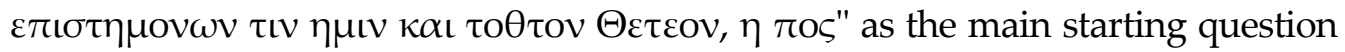
and mention some of its qualities. The form of this question in this specific manner presents some alternatives and at the same time requests for choosing the true one. Now with giving the pertinent specific content to these mentioned categories the question becomes more concrete and clear. Accordingly, it may be said that the Stranger/Guest gives in an explicit way the related alternatives and with proper naming of one of them hints at the desired alternative which the respondent has to choose - a research lesson. At this point it is natural to call it a kind of "whether - question" in which the options are mentioned and within this boundary the Young Socrates should decide about the true appropriate answer. In other words, dealing with the whoness and whatness of statesman as a "which - question"10 the general purpose of this dialogue will be done through a "dialectical method." This kind of operation has both pedagogical and research benefits for the questioner and young answerer in their conversation with each other. As an overall result we may say that the form of this "whether -

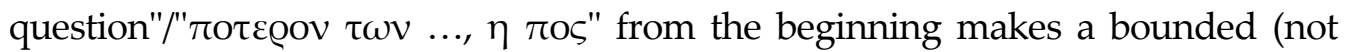
unbounded and general) dialogue with a specific aim and in this context the engaged interlocutors understand and agree upon the question and how it should go on. Thereby the respondent has not a wide imaginable range of alternatives to mention and after a long process of thinking and discussing make his choice and give it as his preferred and perhaps correct answer. Thus the form of question (apart from the general quality of this dialogue) is dialectical and thereby it has relevancy also with the overall and dominant method the dialogue which is essentially based on and functions within A/Other-Than-A format.

At first by dichotomies the genus and difference of statesman becomes clear then in order to introduce the logical individual, "analogy" enters on the scene. Of course there can be multiple related familiar examples each with their own specific results for our searched intended category but among these weaving/the weaver has a special and outstanding position therefore it is worthwhile to stand on it.

9. Lewis Campbell, Sophistes and Politicus of Plato (Clarendon Press, 1867), 179.

10. Gerasimos Xenophon Santas, Socrates, the Arguments of the Philosophers (Routeldge, 2008), 74, 75. 
Vol. 3, No. 3 Younesie: Justifying Logic of Plato for Stranger's Method in Politicus

\section{Bibliography}

Campbell, Lewis. Sophistes and Politicus of Plato. Clarendon Press, 1867.

Khansari. M. A Dictionary of Logical Terms. Foundation of Iranian Culture, 1980.

Kneale, William, and Martha Kneale. The Development of Logic. Oxford University Press, 1985.

Lane, Melisa S. Method and Politics in Plato's Statesman. Cambridge Classical Studies, 1998.

Lutoslawski, Wincenty. The Origin and Growth of Plato's Logic. Longmans, 1897.

Santas, Gerasimos Xenophon. Socrates, the Arguments of the Philosophers. Routeldge, 2008.

Sayre, Kenneth M. Metaphysics and method in Plato's Statesman. Cambridge University Press, 2006. 